\title{
TOWARD REDUCED REPRESENTATION OF MIXING STATE FOR SIMULATING AEROSOL EFFECTS ON CLIMATE
}

Laura Fierce, Nicole Riemer, and Tami C. Bond

\section{A benchmarking framework reveals the extent to which the chemical composition of particles} must be resolved to accurately represent aerosol radiative effects and cloud interactions.

A mbient measurements show tremendous variation in composition between particles (Schwarz et al. 2008; Moffet et al. 2008; Liu et al. 2013; Healy et al. 2014), even for particles of the same size. This variability reflects differences in emission sources (Sodeman et al. 2005; Toner et al. 2006; Healy et al. 2012) and in the aging that each particle experiences during transport (Whiteaker et al. 2002; Johnson et al. 2005; Wang et al. 2010; Cheng et al. 2012). This particle-level variation in composition cannot be

AFFILIATIONS: FieRCE-Environmental and Climate Sciences Department, Brookhaven National Laboratory, Upton, New York; RIEMER-Department of Atmospheric Sciences, University of Illinois at Urbana-Champaign, Urbana, Illinois; BoND-Department of Civil and Environmental Engineering, University of Illinois at Urbana-Champaign, Urbana, Illinois

CORRESPONDING AUTHOR: Laura Fierce, Ifierce@bnl.gov

The abstract for this article can be found in this issue, following the table of contents.

DOI:10.II75/BAMS-D-16-0028.I

A supplement to this article is available online (I0.II75/BAMS-D-16-0028.2).

In final form 18 August 2016

(C2017 American Meteorological Society resolved in large-scale chemical transport models, so models assume simple representations of the aerosol mixing state. It is not known to what extent mixing state needs to be resolved to accurately represent aerosol properties relevant to climate, specifically aerosol absorption and scattering, which govern direct radiative forcing, and cloud condensation nuclei (CCN) concentrations, which govern indirect radiative forcing.

Depending on the makeup of a particular aerosol population, differences in composition between particles may influence aerosol radiative effects. For example, whereas most particles contain predominantly light-scattering material and cause an overall cooling effect on the climate, particles containing absorbing components, such as black carbon (BC), exert a warming effect on the climate. Aerosol direct radiative effects depend not only on the overall abundances of absorbing and scattering species, but also the distribution of these species among individual particles (Jacobson 2001; Chung et al. 2011). Similarly, indirect radiative effects from cloud perturbations depend on particles' ability to form cloud droplets. In air supersaturated with water vapor, particles may serve as seeds for cloud droplet nucleation, and particles 
that are large or hygroscopic become $\mathrm{CCN}$ at lower supersaturation levels than particles that are small or hydrophobic, respectively. In some cases, resolving these differences in hygroscopic properties between particles affects estimates of CCN concentrations (Cubison et al. 2008; Ervens et al. 2010). Here we show that, despite these complexities, models may not need to fully resolve particle microphysical properties to accurately capture aerosol climate impacts.

Many aerosol schemes have been developed to simulate the evolution of particle size and composition (e.g., Wexler et al. 1994; Jacobson 1997; Binkowski and Roselle 2003; Bauer et al. 2008), and the amount of composition detail tracked has tended to increase over time. The earliest aerosol models simulated total aerosol mass in each grid cell, without resolving the particle size distribution or mixing state. Instead, all particles in a given location were assumed to contain only a single species (e.g., Penner et al. 1998; Cooke et al. 1999), known as the fully external mixture approximation, or to have the same composition (e.g., Haywood et al. 1997; Myhre et al. 1998; Lesins et al. 2002), known as the fully internal mixture approximation. Since then, many chemical transport models have moved to include aerosol schemes that simulate the evolution of the particle size distribution, while also resolving some mixingstate information. For example, sectional schemes simulate particles within separate size bins (e.g., Wexler et al. 1994; Jacobson 1997), assuming that particles within each size bin have the same composition. Modal schemes simulate separate subpopulations or modes (e.g., Binkowski and Roselle 2003; Bauer et al. 2008), assuming that particles in the same mode have the same composition. Some modal schemes distinguish between particles in different size regimes, such as nucleation, accumulation, and coarse modes, without resolving differences in composition between particles within the same size regime (e.g., Ghan et al. 2001; Binkowski and Roselle 2003). Given the unique characteristics of $\mathrm{BC}$, such as its strong light absorption, some modal schemes resolve BC-containing particles in separate modes (e.g., Stier et al. 2005; Bauer et al. 2008). Similarly, some sectional schemes have expanded to track multiple populations (e.g., Kleeman and Cass 2001; Jacobson 2002), often representing absorbing components like BC in separate populations, or to track multivariate distributions using a sectional framework (e.g., Oshima et al. 2009; Matsui et al. 2013; Zhu et al. 2015), where particles are binned as a function of size and some other independent variable (e.g., BC mass fraction).
Although chemical transport models now include complex aerosol representations that better resolve variability in particle composition, even the most sophisticated aerosol schemes in global models do not fully resolve the aerosol mixing state. Computationally efficient aerosol representations are needed for regional-scale and global-scale models of aerosol transport and fate, including those used in climate simulations, but the minimal representation of the aerosol mixing state required to represent climate-relevant properties has not yet been identified. This paper describes an approach to systematically evaluate reduced mixing-state representations using a particle-resolved model as a benchmark.

\section{FRAMEWORK FOR EVALUATING NU. MERICAL REPRESENTATIONS OF THE AEROSOL MIXING STATE. A common practice} in many computational science communities is to develop well-defined benchmark cases with which new methods can be verified (e.g., Belytschko et al. 1985; Bathe and Ledezma 2007). For simulation of the aerosol mixing state, this practice has been applied only in limited cases (McGraw et al. 2008; Zaveri et al. 2010) because, until recently, a benchmark model did not exist that fully resolved particle composition. In this study, we apply the Particle Monte Carlo (PartMC) model (Riemer et al. 2009) coupled to the Model for Simulating Aerosol Interactions and Chemistry (MOSAIC; Zaveri et al. 2008) to simulate the evolution of diverse particle populations under a range of atmospheric conditions. For different stages of aerosol evolution, we quantified the errors in optical properties and $\mathrm{CCN}$ concentrations from simplified mixing-state representations. PartMC-MOSAIC is uniquely suited for benchmarking approximations of particle composition because it is the only model that fully resolves the aerosol mixing state.

The benchmarking procedure for evaluating reduced mixing-state representations of aerosol composition is as follows:

1) We simulated the evolution of a population of fresh combustion particles, which are strongly absorbing and hydrophobic, emitted into air parcels that initially contained nonabsorbing and hygroscopic background aerosol in 100 scenarios using PartMC-MOSAIC.

2) We computed the absorption coefficient, the scattering coefficient, and the number concentration of CCN using the per-particle composition from PartMC-MOSAIC (Fig. 1a) for populations as the particles evolved in time. 
3) We then projected each particle-resolved population according to the treatment in each reduced representation (Figs. 1b-e) and calculated the same climate-relevant properties.

The benchmarking dataset comprises particle populations sampled every $10 \mathrm{~min}$ in simulations, each 1 week in duration (about 14,000 populations, each containing 5,000 particles). A good comparison between climaterelevant properties from a reduced representation and those from the particle-resolved representation indicates that the reduced representation is adequate.

Figure 1 shows how a complex population simulated by the particle-resolved model (Fig. 1a) would appear under four reduced representations of particle composition:

1) fully mixed: assume all particles have the same composition (Fig. 1b);

2) size resolved: assume particles within a given size range have the same composition, similar to sectional schemes (Fig. 1c);

3) type resolved: divide the particles into three classes, defined based on their source and assume particles within a given class are fully mixed (Fig. 1d); and

4) size and type resolved: divide the particles into three classes and assume size-resolved composition within each class (Fig. 1e).

Figure 1 demonstrates the simplifications described above for a sample particle-resolved population.
Figure 1a reflects the particle-level variation in composition that is simulated by PartMC-MOSAIC. PartMC-MOSAIC tracks the mass of $k=1, \ldots, A$ constituent aerosol species in each particle $i=1, \ldots, N_{p}$, where $A$ is the total number of aerosol species, including water, and $N_{p}$ is the total number of particles in the population. The mass of each component in each particle is given by $\mu_{k, i}$ and the mass composition of each particle is represented by the vector $\boldsymbol{\mu}_{i}=\left[\mu_{1, i}, \ldots, \mu_{k, i}, \ldots, \mu_{A, i}\right]$, where water is the $A$ th species. To model light absorption as a function of relative humidity, which depends on water uptake, the mass of water contained in each particle $\mu_{i, A}$ is calculated as a postprocessing step using the $\kappa$-Köhler model (Petters and Kreidenweis 2007). Additional details on the model setup and acquisition of the model code are provided in the online supplement.

The reduced aerosol representations are constructed by averaging across the particle-resolved populations in different ways. In each case, all particles maintain their original total dry mass. For example, the mass of species $k$ contained in particle $i$ under the fully mixed approximation $\tilde{\mu}_{k, i}$ is computed as follows:

$$
\tilde{\mu}_{k, i}=\underbrace{\left(\sum_{k}^{A-1} \mu_{k, i}\right)}_{\text {Dry particle mass }} \underbrace{\left(\frac{\sum_{j}^{N_{p}} \mu_{k, j}}{\sum_{j}^{N_{p}} \sum_{k}^{A-1} \mu_{k, j}}\right)}_{\begin{array}{c}
\text { Average dry mass } \\
\text { fraction of species } k
\end{array}} .
$$

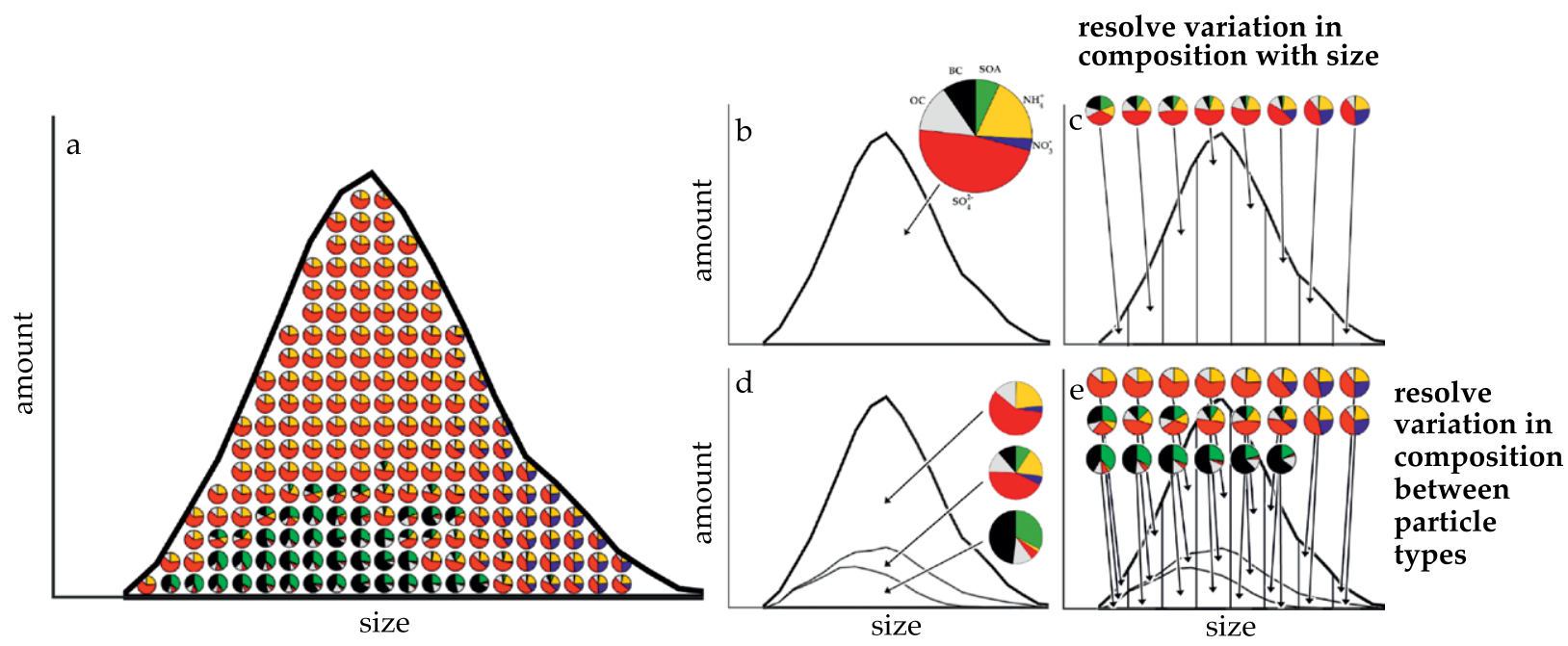

Fig. I. Model representations of aerosol composition. For the same particle size distribution, we compare the (a) particle-resolved representation of composition with four simplified representations: (b) assuming uniform composition across all particles, (c) assuming uniform composition for particles within a size bin, (d) assuming uniform composition for particles of the same type, and (e) assuming size-resolved composition for particles of the same type. 

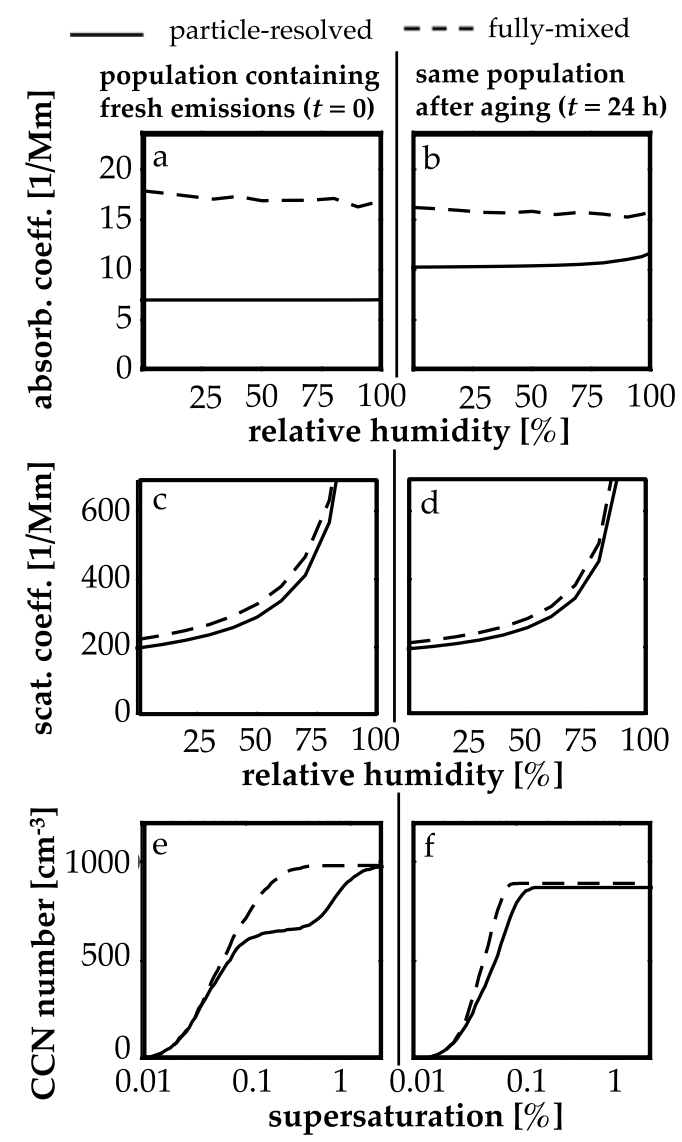

Fig. 2. (top) Absorption coefficient as a function of relative humidity for (a) a population containing fresh emissions $(t=0)$ and $(b)$ the same population after $24 \mathrm{~h}$ of aging. (middle) Scattering coefficient as a function of relative humidity for the population at (c) $t=0$ and (d) $t=24 \mathrm{~h}$ and (bottom) number concentration of CCN as a function of water vapor supersaturation level for the population at (e) $t=0$ and (f) $t=24 \mathrm{~h}$.

The mass composition under the other reduced representations shown in Fig. 1 are computed in a similar manner, by applying the averaging procedure in Eq. (1) to particles of the same type or of the same size.

The four reduced representations (Figs. 1b-e) are constructed so that the overall size distribution and the total mass concentration of each species are the same as the particle-resolved population. Hence, the populations differ only in the distribution of aerosol components between individual particles. This treatment isolates errors that are introduced by simplifying the aerosol mixing state. In the type-resolved representations, we define three classes based on particle origin: 1) combustion particles that have not coagulated with background particles, 2) background particles that have not coagulated with combustion particles, and 3) particles that form by coagulation between combustion and background particles. Resolving composition by particle type has been applied in source-oriented aerosol models (e.g., Kleeman and Cass 2001) and some models that represent separate aerosol subpopulations (e.g., Jacobson 2002; Bauer et al. 2008).

For both the particle-resolved and reduced representations, the light-absorption cross section $\sigma_{\text {abs }, i}$ and scattering cross section $\sigma_{\text {scat }, i}$ were computed for each particle $i=1, \ldots, N_{p}$ from the per-particle mass composition using Mie's solution to Maxwell's equations. The Mie solution takes as inputs the wet particle volume, the particle's effective relative permittivity, and the wavelength of light. The volume of dry aerosol components is computed using the density of each species and the volume of water contained in each particle is then computed using the $\kappa$-Köhler model (see online supplement). BC-containing particles are modeled as an effective medium using the dynamic effective medium approximation (DEMA; Chylek et al. 1984; Jacobson 2006), such that particles are assumed to contain one or more randomly distributed inclusions within an otherwise homogenous particle, and BC-free particles are assumed to be completely homogeneous. The absorption coefficient $b_{\text {abs }}$ and scattering coefficient $b_{\text {scat }}$ were then computed as the sum over $\sigma_{\text {abs }, i}$ and $\sigma_{\text {scat }, i}$, respectively, per volume of air.

Similarly, the critical supersaturation $s_{c, i}$ at which each particle becomes CCN active was computed for each particle $i$ using the $\kappa$-Köhler model, which depends on a particle's overall dry volume, its effective hygroscopicity parameter $\kappa_{i}$, and environmental properties (see online supplement). The effective hygroscopicity parameter is the volume-weighted average of the hygroscopicity parameter $\kappa$ of the particle's constituent aerosol species, given in Table ES3 of the online supplement. The number concentration of CCN $\left(N_{\mathrm{CCN}}\right)$ at a specific environmental supersaturation $s$ is then computed as the total number of particles per volume having a critical supersaturation $s_{c, i}<s$.

\section{IS THE FULLY MIXED APPROXIMATION} ADEQUATE? Before evaluating each reduced representation of composition, we first quantify error in the simplest representation, the fully mixed approximation (Fig. 1b), to explore whether aerosol optical properties or $\mathrm{CCN}$ activity can be represented without resolving any differences in composition between particles. Under the fully mixed approximation, diversity in composition between particles is neglected entirely and only the total amount of each aerosol component is tracked. Figure 2 shows $\mathrm{CCN}$ and optical properties for a baseline scenario as it would appear immediately after the introduction of fresh particle emissions (Fig. 2, left) and for the 
population as it would appear after all particles have aged for $24 \mathrm{~h}$ (Fig. 2, right), where solid and dashed lines show the particle-resolved and fully mixed representations of the population, respectively.

The difference in the absorption coefficient between the particle-resolved and fully mixed representations (Figs. 2a,b) shows that light absorption cannot be adequately represented using the fully mixed approximation, regardless of the extent of atmospheric processing. The error is caused by differences in model representations of the amount of $\mathrm{BC}$ and coating material contained in each particle. Light absorption by $\mathrm{BC}$ is enhanced when $\mathrm{BC}$ and nonabsorbing components coexist in the same particle (Jacobson 2001; Bond et al. 2006) and absorption by BC is often further increased if particles take up water at high relative humidity (Mikhailov et al. 2006; Jacobson 2012). The ratio of BC to coating material varies between individual particles under the particle-resolved representation, with some particles containing large volume fractions of $\mathrm{BC}$ with only small amounts of coating and others containing no BC at all. Black carbon is artificially distributed across the entire population under the fully mixed approximation, such that every particle contains some $\mathrm{BC}$ and a large volume fraction of coating material, leading to overestimation in light absorption. The scattering coefficient, on the other hand, can be adequately represented without resolving the aerosol mixing state (Figs. 2c,d). Because even the most simplified representation produces only small errors in the scattering coefficient, we will not continue to evaluate this quantity.

Whereas variation in composition across the particle population affects model estimates of aerosol absorption, CCN activity can be modeled with high accuracy once emitted particles have aged. Figure $2 \mathrm{e}$ represents particle populations near emission sources, where freshly emitted, hydrophobic particles are externally mixed from the more-hygroscopic background aerosol. If all particles are assumed to have uniform composition, the hygroscopic material is artificially spread over the emitted particles, leading to overestimation of modeled CCN concentrations at some cloud supersaturation levels (Fig. 2e). On the other hand, after all particles have aged (Fig. 2e), the hygroscopicity parameter is nearly uniform across the entire population. As a result, water uptake varies with size only and not with composition after all particles have aged, after which the fully mixed approximation (dashed line) is sufficient to model CCN activity. This result is consistent with ambient observations in areas that are not strongly influenced by local emissions (Dusek et al. 2006; Ervens et al. 2010).
TIME SCALE FOR INTERNAL MIXING WITH RESPECT TO HYGROSCOPIC PROPERTIES. Emitted particles become internally mixed with background aerosol soon after emission through condensation of semivolatile gases and coagulation with preexisting background particles. Expanding the analysis shown in Figs. $2 \mathrm{e}$ and $2 \mathrm{f}$ to all 100 sensitivity scenarios, we find that the error in $\mathrm{CCN}$ concentrations between the particle-resolved and fully mixed approximation always decays over time, with a characteristic $e$-folding time $\tau_{\text {mix }}$ that depends on local conditions. The value of $\tau_{\text {mix }}$ characterizes the transition to an internally mixed population, for which CCN concentrations can be represented without resolving particle composition.

The series of 100 scenarios represent a range of atmospheric conditions. Twenty-eight input parameters were varied, including gas emissions, the characteristics of emitted and background particles, and meteorological conditions. The 100 scenarios were sampled using Latin hypercube sampling (McKay et al. 1979), which is a statistical method for generating combinations of input variables that span a given variable space. The input parameters assigned in the baseline and sensitivity scenarios are included in the online supplement.

The error in the number concentration of $\mathrm{CCN}$ for a specific scenario $q$ at time $t$ is computed as

$$
\varepsilon_{\mathrm{CCN}, q}(t)=\frac{\int_{0}^{\infty}\left[\tilde{N}_{\mathrm{CCN}, q}(t, s)-N_{\mathrm{CCN}, q}(t, s)\right] d s}{\int_{0}^{\infty} N_{\mathrm{CCN}, q}(t, s) d s},
$$

where $N_{\mathrm{CCN}}$ and $\tilde{N}_{\mathrm{CCN}}$ are the number concentration of CCN computed using the particle-resolved composition and reduced representation of composition, respectively.

We found that error in the number concentration of $\mathrm{CCN}$ from the fully mixed approximation $\varepsilon_{\mathrm{CCN}}(t)$ decays exponentially over time according to a first-order time scale $\tau_{\text {mix }}$, such that the error at time $t$ is given by

$$
\varepsilon_{\mathrm{CCN}}(t)=\varepsilon_{\mathrm{CCN}}\left(t_{0}\right) \exp \left[-\int_{t_{0}}^{t} \frac{1}{\tau_{\text {mix }}(t)} d t\right] \text {, }
$$

where $\varepsilon_{\mathrm{CCN}}\left(t_{0}\right)$ is the error at the start of the simulation, when freshly emitted particles first enter the atmosphere.

The error in CCN activity from the fully mixed approximation decreased because of separate effects of condensation and coagulation. By performing a nonlinear parametric regression on the entire 


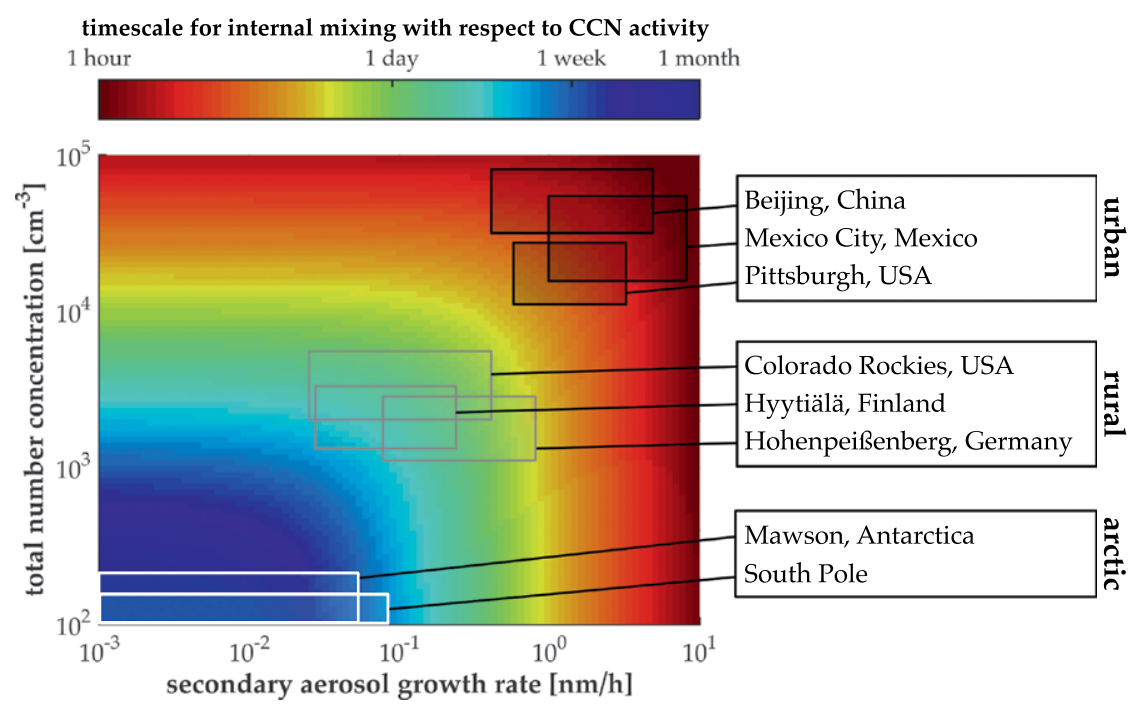

FIG. 3. Estimated e-folding time $\tau_{\text {mix }}$ for the error in $\mathbf{C C N}$ activity from the internal mixture approximation. Approximate ranges in condensational growth rates and number concentrations that were inferred from measurements are indicated for specific locations (see online supplement). Values for $\tau_{\text {mix }}$ are shorter than an hour in most urban areas, indicating the particles emitted in these areas become internally mixed soon after emission. Only in very remote regions, such as the Arctic, is $\tau_{\text {mix }}$ longer than a few days. measurements in urban areas (e.g., Moffet and Prather 2009). Only under conditions with very slow condensational growth and low particle concentrations do freshly emitted particles remain externally mixed with respect to their hygroscopic properties for longer than a week, and these conditions occur only in remote areas that have few fresh particle emissions. We are not aware of any observations in remote areas that quantify time scales for internal mixing based on observations, so additional measurements are needed to constrain the model-derived mixing time scales in these remote areas. benchmarking dataset, we found that $\tau_{\text {mix }}$ is inversely related to the combination of two independent variables characteristic of the local environment: the condensational growth rate and the total particle number concentration. The relationship between $\tau_{\text {mix }}$ and these two governing variables is shown in Fig. 3 . The $e$-folding time scale $\tau_{\text {mix }}$ can be expressed as a function of the condensation rate $I_{\text {cond }}(t)$ and the overall aerosol number concentration $N(t)$ :

$$
\tau_{\text {mix }} \approx\left(k_{\text {cond }} I_{\text {cond }}+k_{\text {coag }} N\right)^{-1} \text {, }
$$

where $k_{\text {cond }}=0.1 \mathrm{~nm}^{-1}$ and $k_{\text {coag }}=6 \times 10^{-6} \mathrm{~cm}^{3} \mathrm{~h}^{-1}$, as determined from the regression, such that $\tau_{\text {mix }}$ decreases as either $I_{\text {cond }}$ or $N$ increase. This first-order decay model reproduces the evolution of error from the fully mixed approximation with high accuracy $\left(R^{2}=85 \%\right)$. The regression procedure is described in the online supplement.

To estimate the values of $\tau_{\text {mix }}$ expected in the atmosphere, we inferred the governing variables from ambient observations in various locations (see online supplement). If the condensational growth rate exceeds $1 \mathrm{~nm} \mathrm{~h}^{-1}$, as is typical of many urban areas, and if no fresh particles are entering the population, the particle population becomes internally mixed within a few hours, regardless of the local number concentration. These values for $\tau_{\text {mix }}$ are consistent with aging time scales based on particle-resolved

\section{TOWARD MINIMAL RESOLUTION OF} PARTICLE COMPOSITION. We have shown that the fully mixed approximation is not sufficient to represent aerosol absorption or, for populations strongly influenced by fresh emissions, to represent $\mathrm{CCN}$ activity. This raises the question, what resolution is needed to represent climate-relevant aerosol properties across all populations? In this section, we evaluate whether better resolution of particle composition improves the representation of $\mathrm{CCN}$ activity and optical properties. To accomplish this, we compare the reduced representations of composition shown in Figs. 1b-e with the particle-resolved representation (Fig. 1a).

Figure 4 summarizes error in climate-relevant properties across the entire benchmarking dataset. The relative error in particle optical properties or $\mathrm{CCN}$ activity caused by a reduced representation of particle composition is quantified as the difference between quantities computed using particle-resolved composition and using a reduced representation of composition [Eq. (2)]. The normalized mean factor bias $B_{\mathrm{NMF}}$ (Yu et al. 2006; see online supplement) is then given by the mean of $\varepsilon_{\mathrm{CCN}}(t)$ across all scenarios and all selected time steps, weighted by the integral over $N_{\mathrm{CCN}}(t, s)$ from the particle-resolved model.

Populations containing freshly emitted particles $(t=0$, black dots) are compared separately from populations containing aged particles only $\left(t>\tau_{\text {mix }}\right.$, 
white dots). The parameterization of $\tau_{\text {mix }}$ (Fig. 3) indeed reflects the time scale for particles to become sufficiently mixed that differences in composition need not be resolved to capture their $\mathrm{CCN}$ activity, as shown by the accurate representation of CCN activity for any representation once particles have aged for longer than $\tau_{\text {mix }}$.

Although CCN activity is insensitive to mixing state after all particles have aged, aerosol absorption depends strongly on mixing state even after days of atmospheric aging. After emitted particles have aged, all reduced representations yield some error in the absorption coefficient, indicating that these reduced representations do not fully resolve the variability in composition simulated by the particle-resolved model. In the reduced representations that do not resolve differences between particle types, such as the fully mixed and size-resolved representations, error in modeled absorption decreases as particles age because variability in $\mathrm{BC}$ volume fraction for the entire population, including both background and combustion particles, tends to decrease over time. On the other hand, the type-resolved and type-and-size-resolved representations accurately reproduce the absorption coefficient of the particle-resolved population at the start of each simulation, but error in modeled absorption increases as emitted particles age. In the simulations described here, the aerosol populations initially consist of two externally mixed particle types, each containing little or no variability in composition. The optical properties of these populations with uniform composition are captured well by both the type-resolved and type-andsize-resolved representations. As the two populations mix, variability in the ratio of $\mathrm{BC}$ to coating material increases within populations of emitted particles, leading to overestimation of modeled absorption when type-resolved or type-and-size-resolved representation is used.

CCN concentrations are sensitive to the representation of composition only in areas strongly influenced by local emissions. At the start of the simulations $(t=0)$, the fully mixed and size-resolved normalized mean bias in absorption coefficient

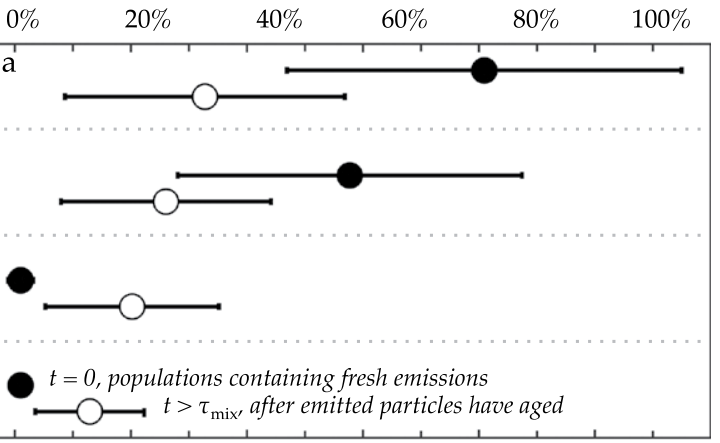

normalized mean bias in $\mathrm{CCN}$ concentration

$\begin{array}{llllll}0 \% & 20 \% & 40 \% & 60 \% & 80 \% & 100 \%\end{array}$

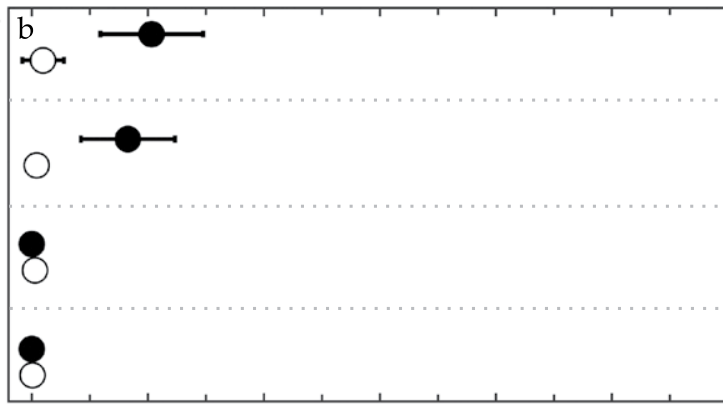

Fig. 4. Normalized mean factor bias (Yu et al. 2006) in (a) aerosol absoefficient and (b) number concentration of CCN for populapopulations in which all particles had undergone atmospheric aging ( $t>\tau_{\text {mix }}$, white dots). Error bars show the $90 \%$ confidence intervals across the simulations.

representations cause a mean overestimation in $\mathrm{CCN}$ concentrations by $21 \%$ and $17 \%$, respectively, as indicated by the black dots in Fig. 4b. Only representations that resolve differences in particle type (Figs. 1d,e) are able to capture the differences in particle hygroscopic properties, which is important for populations containing freshly emitted particles. On the other hand, $\mathrm{CCN}$ concentrations are not affected by mixing-state approximations after emitted particles have aged.

IMPLICATIONS. Many chemical transport models now include aerosol schemes that simulate the evolution of particle physical and chemical properties, with varying degrees of resolution, but it was previously not known to what extent chemical composition needed to be resolved for accurate representation of aerosol effects related to climate. Although aerosol populations are composed of complex particles of varied chemical composition (Schwarz et al. 2008; Moffet et al. 2008; Liu et al. 2013; Healy et al. 2014), we show that particle-level variation in composition affects CCN activity only under certain circumstances. 
We confirm findings from ambient observations (Dusek et al. 2006; Ervens et al. 2010) that the fully mixed approximation is sufficient for modeling CCN activity of populations that are not strongly affected by fresh emissions. The present study puts these observations into context by quantifying the time scale for this fully mixed approximation to become valid. We show that, in many locations, the fully mixed approximation becomes valid for modeling CCN activity within hours after particles are emitted. The rate of this transformation is characterized by a first-order aging time scale $\tau_{\text {mix }}$, which depends on quantities that are easily determined from global models and ambient measurements.

More detailed mixing-state treatments are needed to represent absorption by populations containing fresh or aged particles and to represent the hygroscopic properties of populations containing freshly emitted particles. Populations containing fresh emissions can be modeled with greater accuracy if schemes resolve differences between particle types, which is possible in some modal schemes (e.g., Stier et al. 2005; Bauer et al. 2008) or multidistribution sectional schemes (e.g., Kleeman and Cass 2001; Jacobson 2002). Bulk schemes that assume fully mixed populations and single-distribution sectional schemes artificially distribute $\mathrm{BC}$ mass among $\mathrm{BC}$-containing and $\mathrm{BC}$-free particles, causing overestimation in absorption due to artificial mixing of $\mathrm{BC}$ with non-BC components. This artificial mixing also causes freshly emitted particles to appear more hygroscopic than they actually are, leading to an overestimation in $\mathrm{CCN}$ activity in populations that are strongly influenced by local emissions. This finding suggests that, for both modal and sectional schemes, absorption and $\mathrm{CCN}$ activity can be predicted with greater accuracy if populations containing $\mathrm{BC}$ are represented separately from $\mathrm{BC}$-free populations. Whereas this study isolates error associated with model representations of the particle mixing state, a full evaluation of modal and sectional schemes would include side-byside aerosol dynamics simulations and would assess errors associated with modeled size distributions as well as mixing state. Further, even though we used a highly detailed model simulation for benchmarking, no model represents reality perfectly. The mixingstate evaluation described in this study depends on the extent to which PartMC-MOSAIC, as well as $\kappa$-Köhler and DEMA, represent the evolution of particle characteristics over time.

This procedure of benchmarking reduced models against high-resolution models should complement model evaluation by comparison with observations.
By identifying the approximations that most affect the prediction of climate-relevant properties, this procedure can elucidate the cause for differences between modeled and measured aerosol properties. The approach described here can be extended in future studies to evaluate the importance of mixing state in modeling other aerosol properties, such as ice nucleation and the role of surfactants on $\mathrm{CCN}$ activity. As models become more sophisticated in representing aerosol composition and its effect on climate, this type of benchmarking will become necessary to identify accurate representations of the aerosol mixing state.

ACKNOWLEDGMENTS. This work was supported by the U.S. Environmental Protection Agency (R83504201) and by NASA (NNX09AK66G). Fierce is supported by UCAR under a NOAA Climate and Global Change Postdoctoral Fellowship. The authors are grateful to Steven Ghan for the insightful question that inspired the mixing time scale analysis. We also thank Ernie Lewis and two anonymous reviewers for their helpful comments.

\section{REFERENCES}

Bathe, K.-J., and G. A. Ledezma, 2007: Benchmark problems for incompressible fluid flows with structural interactions. Comput. Struct., 85, 628-644, doi:10.1016/j.compstruc.2007.01.025.

Bauer, S. E., D. L. Wright, D. Koch, E. R. Lewis, R. McGraw, L. S. Chang, S. E. Schwartz, and R. Ruedy, 2008: MATRIX (multiconfiguration Aerosol TRacker of mIXing state): An aerosol microphysical module for global atmospheric models. Atmos. Chem. Phys., 8, 6003-6035, doi:10.5194/acp-8-6003-2008.

Belytschko, T., H. Stolarski, W. K. Liu, N. Carpenter, and J. S. Ong, 1985: Stress projection for membrane and shear locking in shell finite elements. Comput. Methods Appl. Mech. Eng., 51, 221-258, doi:10.1016/0045 -7825(85)90035-0.

Binkowski, F. S., and S. J. Roselle, 2003: Models-3 Community Multiscale Air Quality (CMAQ) model aerosol component: 1. Model description. J. Geophys. Res., 108, 4183, doi:10.1029/2001JD001409.

Bond, T. C., G. Habib, and R. W. Bergstrom, 2006: Limitations in the enhancement of visible light absorption due to mixing state. J. Geophys. Res., 111, D20211, doi:10.1029/2006JD007315.

Cheng, Y. F., and Coauthors, 2012: Size-resolved measurement of the mixing state of soot in the megacity Beijing, China: Diurnal cycle, aging and parameterization. Atmos. Chem. Phys., 12, 4477-4491, doi:10.5194/acp-12-4477-2012. 
Chung, C. E., K. Lee, and D. Müller, 2011: Effect of internal mixture on black carbon radiative forcing. Tellus, 64B, 10925, doi:10.3402/tellusb.v64i0.10925.

Chylek, P., V. Ramaswamy, and R. J. Cheng, 1984: Effect of graphitic carbon on the albedo of clouds. J. Atmos. Sci., 41, 3076-3084, doi:10.1175/1520-0469(1984)041 $<3076$ :EOGCOT>2.0.CO;2.

Cooke, W. F., C. Liousse, H. Cachier, and J. Feichter, 1999: Construction of $\mathrm{a} 1^{\circ} \times 1^{\circ}$ fossil fuel emission data set for carbonaceous aerosol and implementation and radiative impact in the ECHAM4 model. J. Geophys. Res., 104, 22 137-22 162, doi:10.1029/1999JD900187.

Cubison, M., and Coauthors, 2008: The influence of chemical composition and mixing state of Los Angeles urban aerosol on CCN number and cloud properties. Atmos. Chem. Phys., 8, 5649-5667, doi:10.5194 /acp-8-5649-2008.

Dusek, U., and Coauthors, 2006: Size matters more than chemistry for cloud-nucleating ability of aerosol particles. Science, 312, 1375-1378, doi:10.1126 /science.1125261.

Ervens, B., and Coauthors, 2010: CCN predictions using simplified assumptions of organic aerosol composition and mixing state: A synthesis from six different locations. Atmos. Chem. Phys., 10, 4795-4807, doi:10.5194/acp-10-4795-2010.

Ghan, S., N. Laulainen, R. Easter, R. Wagener, S. Nemesure, E. Chapman, Y. Zhang, and R. Leung, 2001: Evaluation of aerosol direct radiative forcing in mirage. J. Geophys. Res., 106, 5295-5316, doi:10.1029/2000JD900502.

Haywood, J. M., D. L. Roberts, A. Slingo, J. M. Edwards, and K. P. Shine, 1997: General circulation model calculations of the direct radiative forcing by anthropogenic sulfate and fossil-fuel soot aerosol. J. Climate, 10, 1562-1577, doi:10.1175/1520-0442 (1997) $010<1562$ :GCMCOT>2.0.CO;2.

Healy, R. M., and Coauthors, 2012: Sources and mixing state of size-resolved elemental carbon particles in a European megacity: Paris. Atmos. Chem. Phys., 12, 1681-1700, doi:10.5194/acp-12-1681-2012.

— , and Coauthors, 2014: Single particle diversity and mixing state measurements. Atmos. Chem. Phys. Discuss., 14, 3973-4005, doi:10.5194 lacpd-14-3973-2014.

Jacobson, M. Z., 1997: Development and application of a new air pollution modeling system-II. Aerosol module structure and design. Atmos. Environ., 31, 131-144, doi:10.1016/1352-2310(96)00202-6.

_ 2001: Strong radiative heating due to the mixing state of black carbon in atmospheric aerosols. Nature, 409, 695-697, doi:10.1038/35055518.

_ 2002: Analysis of aerosol interactions with numerical techniques for solving coagulation, nucleation, condensation, dissolution, and reversible chemistry among multiple size distributions. J. Geophys. Res., 107, 4366, doi:10.1029/2001JD002044.

— 2006 : Effects of externally-through-internallymixed soot inclusions within clouds and precipitation on global climate. J. Phys. Chem. A, 110, 6860-6873, doi:10.1021/jp056391r.

— 2012: Investigating cloud absorption effects: Global absorption properties of black carbon, tar balls, and soil dust in clouds and aerosols. J. Geophys. Res., 117, D06205, doi:10.1029/2011JD017218.

Johnson, K. S., and Coauthors, 2005: Processing of soot in an urban environment: Case study from the Mexico City Metropolitan Area. Atmos. Chem. Phys., 5, 3033-3043, doi:10.5194/acp-5-3033-2005.

Kleeman, M. J., and G. R. Cass, 2001: A 3D Eulerian source-oriented model for an externally mixed aerosol. Environ. Sci. Technol., 35, 4834-4848, doi:10.1021 les010886m.

Lesins, G., P. Chylek, and U. Lohmann, 2002: A study of internal and external mixing scenarios and its effect on aerosol optical properties and direct radiative forcing. J. Geophys. Res., 107, 4094, doi:10.1029/2001JD000973.

Liu, D., and Coauthors, 2013: Ambient black carbon particle hygroscopic properties controlled by mixing state and composition. Atmos. Chem. Phys., 13, 2015-2029, doi:10.5194/acp-13-2015-2013.

Matsui, H., M. Koike, Y. Kondo, N. Moteki, J. D. Fast, and R. A. Zaveri, 2013: Development and validation of a black carbon mixing state resolved threedimensional model: Aging processes and radiative impact. J. Geophys. Res. Atmos., 118, 2304-2326, doi:10.1029/2012JD018446.

McGraw, R., L. Leng, W. Zhu, N. Riemer, and M. West, 2008: Aerosol dynamics using the quadrature method of moments: Comparing several quadrature schemes with particle-resolved simulation. J. Phys. Conf. Ser., 125, 012020, doi:10.1088/1742 $-6596 / 125 / 1 / 012020$.

McKay, M. D., R. J. Beckman, and W. J. Conover, 1979: Comparison of three methods for selecting values of input variables in the analysis of output from a computer code. Technometrics, 21, 239-245, doi:10.1080 /00401706.1979.10489755.

Mikhailov, E., S. Vlasenko, I. Podgorny, V. Ramanathan, and C. Corrigan, 2006: Optical properties of soot-water drop agglomerates: An experimental study. J. Geophys. Res., 111, D07209, doi:10.1029/2005JD006389.

Moffet, R. C., and K. A. Prather, 2009: In-situ measurements of the mixing state and optical properties of soot with implications for radiative forcing estimates. Proc. Natl. Acad. Sci. USA, 106, 11872-11877, doi:10.1073 /pnas.0900040106. 
- X. Qin, T. Rebotier, H. Furutani, and K. A. Prather, 2008: Chemically segregated optical and microphysical properties of ambient aerosols measured in a single-particle mass spectrometer. J. Geophys. Res., 113, D12213, doi:10.1029/2007JD009393.

Myhre, G., F. Stordal, K. Restad, and I. S. Isaksen, 1998: Estimation of the direct radiative forcing due to sulfate and soot aerosols. Tellus, 50B, 463-477, doi:10.3402/tellusb.v50i5.16230.

Oshima, N., M. Koike, Y. Zhang, Y. Kondo, N. Moteki, N. Takegawa, and Y. Miyazaki, 2009: Aging of black carbon in outflow from anthropogenic sources using a mixing state resolved model: Model development and evaluation. J. Geophys. Res., 114, D06210, doi:10.1029/2008JD010680.

Penner, J. E., C. C. Chuang, and K. Grant, 1998: Climate forcing by carbonaceous and sulfate aerosols. Climate Dyn., 14, 839-851, doi:10.1007 /s003820050259.

Petters, M. D., and S. M. Kreidenweis, 2007: A single parameter representation of hygroscopic growth and cloud condensation nucleus activity. Atmos. Chem. Phys., 7, 1961-1971, doi:10.5194/acp-7-1961-2007.

Riemer, N., M. West, R. A. Zaveri, and R. C. Easter, 2009: Simulating the evolution of soot mixing state with a particle-resolved aerosol model. J. Geophys. Res., 114, D09202, doi:10.1029/2008JD011073.

Schwarz, J. P., and Coauthors, 2008: Measurement of the mixing state, mass, and optical size of individual black carbon particles in urban and biomass burning emissions. Geophys. Res. Lett., 35, L13810, doi:10.1029 /2008GL033968.

Sodeman, D. A., S. M. Toner, and K. A. Prather, 2005: Determination of single particle mass spectral signatures from light-duty vehicle emissions. Environ. Sci. Technol., 39, 4569-4580, doi:10.1021 les0489947.

Stier, P., and Coauthors, 2005: The aerosol-climate model ECHAM5-HAM. Atmos. Chem. Phys., 5, 1125-1156, doi:10.5194/acp-5-1125-2005.
Toner, S. M., D. A. Sodeman, and K. A. Prather, 2006: Single particle characterization of ultrafine and accumulation mode particles from heavy duty diesel vehicles using aerosol time-of-flight mass spectrometry. Environ. Sci. Technol., 40, 3912-3921, doi:10.1021/es051455x.

Wang, J., M. J. Cubison, A. Aiken, J. L. Jimenez, and D. R. Collins, 2010: The importance of aerosol mixing state and size-resolved composition on CCN concentration and the variation of the importance with atmospheric aging of aerosols. Atmos. Chem. Phys., 10, 7267-7283, doi:10.5194/acp-10-7267-2010. Wexler, A. S., F. W. Lurmann, and J. H. Seinfeld, 1994: Modelling urban and regional aerosols-I. Model development. Atmos. Environ., 28, 531-546, doi:10.1016/1352-2310(94)90129-5.

Whiteaker, J. R., D. T. Suess, and K. A. Prather, 2002: Effects of meteorological conditions on aerosol composition and mixing state in Bakersfield, CA. Environ. Sci. Technol., 36, 2345-2353, doi:10.1021/es011381z.

Yu, S., B. Eder, R. Dennis, S.-H. Chu, and S. E. Schwartz, 2006: New unbiased symmetric metrics for evaluation of air quality models. Atmos. Sci. Lett., 7, 26-34, doi:10.1002/asl.125.

Zaveri, R., R. Easter, J. Fast, and L. Peters, 2008: Model for simulating aerosol interactions and chemistry (MOSAIC). J. Geophys. Res., 113, D13204, doi:10.1029/2007JD008782.

_ J. C. Barnard, R. C. Easter, N. Riemer, and M. West, 2010: Particle-resolved simulation of aerosol size, composition, mixing state, and the associated optical and cloud condensation nuclei activation properties in an evolving urban plume. J. Geophys. Res., 115, D17210, doi:10.1029/2009JD013616.

Zhu, S., K. Sartelet, and C. Seigneur, 2015: A sizecomposition resolved aerosol model for simulating the dynamics of externally mixed particles: SCRAM (v 1.0). Geosci. Model Dev., 8, 1595-1612, doi:10.5194 /gmd-8-1595-2015. 